\title{
Strengthening Surgical and Anaesthetic Services at District Level in the African Region: Issues, Challenges and Proposed Actions
}

\author{
J B Ndihokubwayo ${ }^{1}$, S O Coulibaly ${ }^{1}$, M N Cherian ${ }^{2}$, M M Ekeke ${ }^{1}$, J Nabyonga ${ }^{1}$, \\ L Musango ${ }^{1}$, T Nkurunziza ${ }^{1}$, C King ${ }^{3}$, I Premaratne ${ }^{4}$, W D Johnson ${ }^{2}$ \\ ${ }^{1}$ WHO/AFRO \\ ${ }^{2} \mathrm{WHO} / \mathrm{HQ}$ \\ ${ }^{3}$ Virginia Commonwealth University School of Medicine, Richmond, Virginia, \\ USA \\ ${ }^{4}$ Harvard College, Massachusetts, USA \\ Correspondence to:Dr. Ndihokubwayo, Email: ndihokubwayoj@who.int \\ https://dx.doi.org/10.4314/ecajs.v22i1.3
}

Health care delivery systems are organized at several levels with the district hospital serving as the first referral for comprehensive care in the majority of countries worldwide. The provision of comprehensive surgical services requires several inputs and tools to be in place, among which are an adequately trained surgical, anaesthesia and obstetric healthcare workforce, infrastructure and functioning equipment, and essential medicines and supplies. These, however, are not in place in the majority of commonly received surgical cases, such as trauma, obstetric, abdominal and orthopedic emergencies, thus limiting the capacity of district hospitals to address them. Global and regional public health initiatives have traditionally neglected the necessity of the provision of surgical services despite the fact that these constitute an essential component of comprehensive primary healthcare $(\mathrm{PHC})^{1}$. In fact, because surgery so frequently cannot be safely postponed, this deficiency prevents the transfer of patients to a secondary or tertiarylevel hospital where further care can be provided. ${ }^{2}$

\section{Introduction}

In 2004, $11 \%$ of the world's Disability Adjusted Life Years (DALYs) were due to surgically treatable conditions, with Southeast Asia and Africa accounting for $54 \%$ of these cases. The delays faced by patients needing surgical care, referrals to far-off higher level of care health facilities and the necessity of seeking care in overloaded tertiary hospitals further contribute to the grim outcome statistics. For example, the average maternal mortality ratio (MMR) for the African Region (AFRO) in 2010 was 480 for every 100,000 live births3; a significant portion of this was accounted for by delivery complications. In addition, about 5.8 million

\footnotetext{
${ }^{1}$ World Health Organization. The World Health Report (2008). Primary Health Care: Now more than ever

${ }^{2}$ World Health Organization (2009) World Health Statistics 2009. Available:

http://www.who.int/whosis/whostat/2009/en/index.html. Accessed: 20 March 2014).

${ }^{3}$ Cause-specific mortality and morbidity: Maternal mortality ratio. Data by WHO region.

http://apps.who.int/gho/data/view.main.1370?lang=en.
} 
people die each year as a result of injuries. This accounts for $10 \%$ of the world's deaths, $32 \%$ more than the number of fatalities that result from malaria, tuberculosis, and HIV/AIDS combined. ${ }^{4}$ Poor access to timely surgical services, particularly at rural facilities, turns minor surgical pathologies into lethal conditions and a broad range of treatable surgical conditions subsequently result in death and disability. ${ }^{5}$

The importance of strengthening surgical services at the district referral level has been recognized by Member States. Several initiatives have addressed this, among which are the WHO Emergency and Essential Surgical Care (EESC) Programme developed in 2004, the WHO Global Initiative on Emergency and Essential Surgical Care (GIEESC) developed in 2005 and the WHO Integrated Management for Emergency and Essential Surgical Care (IMEESC) Toolkit developed in 2007. 6,7 Countries have also intensified actions by training general practitioners or non-physician caregivers to perform many emergency and essential surgical care procedures.Most recently, the World Health Assembly unanimously passed Resolution 68.15: Strengthening emergency and essential surgical care and anaesthesia as a component of universal health coverage ${ }^{8}$.

Despite these efforts, the limited capacity of district referral facilities to deliver essential surgical services still persists. This paper highlights a number of these specific issues and associated challenges of delivering effective surgical services at the district referral level in the African region and proposes several actions that may be taken in response.

Issues

Weak Governance: Inadequate provision for surgical services in national health policies and plans, as well as the perception that these services are resource intensive and costly, are issues that must be overcome in the majority of countries in AFRO. At present, there is not enough advocacy or investment to significantly improve delivery of life-saving and disabilitypreventing surgical services in the district level health system.

Weak human resources:Existing data show that AFRO faces an extreme shortage of trained health workers, particularly surgical, anaesthetic and obstetric specialists. ${ }^{9,10,1112,13,14}$ This

\footnotetext{
${ }^{4}$ WHO Violence and Injury Prevention Key Facts (2004)

http://www.who.int/violence_injury_prevention/key_facts/VIP_key_facts.pdf?ua=1.

${ }^{5}$ McIntyre T, Zenilman M. (2010) “Globalization of Surgery: Let's get serious.” Arch Surg. 145(8):715-716; http://archsurg.jamanetwork.com/article. aspx?articleid=406139.

${ }^{6}$ Emergency and essential surgical care: WHO Global Initiative for Emergency and Essential Surgical Care (GIEESC). WHO Web site: www.who.int/surgery.

${ }^{7}$ Adam L. Kushner, et al. (2010) Addressing the Millennium Development Goals from a Surgical Perspective; Essential Surgery and Anesthesia in 8 Low- and Middle-Income Countries; Arch Surg; 145(2):154-160.

${ }^{8}$ WHA Resolution 68.15(http://apps.who.int/medicinedocs/documents/s21904en/s21904en.pdf)

${ }^{9}$ Chen L, Evans T, Anand S, Boufford JI, Brown H, et al. (2004) Human resources for health: overcoming the crisis. Lancet 364: 1984-1990.

${ }^{10}$ Lucas AO (2005) Human resources for health in Africa. Br Med J 331: 1037-1038. 15. REF Watters DA, Bayley AC (1987) Training doctors and surgeons to meet the surgical needs of Africa.Br Med J Clin Res Ed 295: 761-763. 13,14.

${ }^{11}$ Contini S (2007) Surgery in developing countries: why and how to meet surgical needs worldwide. Acta Biomed 78:4-5.
} 
shortage of trained staff combined with poor working conditions, heavy workload, low staff morale and inadequate professional career development for these specialists is recognized as one of the major causes of the inability to provide appropriate surgical, anaesthetic and obstetric care. In addition, task-shifting modules, which are required to empower health care workers to provide emergency and essential surgical and anaesthetic care at the district level, are not part of the curricula of most training institutions.

Weak infrastructure: There are severe shortages in all aspects of surgical care systems at the district level facilities, including infrastructure such as safe anaesthesia and surgical equipment ${ }^{15}$, clean running water, continuous oxygen or pulse oximetry ${ }^{16}$, and reliable electricity for the safe delivery of surgical interventions. ${ }^{17}$ This lack of appropriate infrastructure precludes attracting qualified surgical and anaesthetic workforce. A survey in 22 low- and middle-income countries (LMICs) ${ }^{18}$ (including 14 countries ${ }^{i}$ in AFRO) reported gaps in access to safe anaesthesia services such as oxygen supply, pulse-oximetry and a functioning safe anaesthesia machine.

Limited access to surgical and anaesthetic services: The unavailability of surgical services, high rates of trauma and obstetric complications, and the large backlog of untreated surgical diseases together create an enormous undue burden on the district level facility. Surgical care is usually concentrated in overloaded specialist referral hospitals that are not accessible to patients who are unable or unwilling to travel. This, coupled with weak referral systems, often result in patients from remote or impoverished communities arriving the referral healthcare facility in a relatively advanced state of disease, long past whatever curative window was once available. ${ }^{19}$ Many district hospitals also lack the capacity to provide a full range of appropriate surgical services, including obstetric services. ${ }^{20,20,21}$ The obstacles to

12 Beveridge M, Howard A (2004). The burden of orthopedic disease in developing countries. J Bone Joint Surg Am 86-A: 1819-1822.

${ }^{13}$ Ozgediz D, Kijjambu, S, et al (2008) Africa's neglected surgical workforce crisis. The Lancet (371).

${ }^{14}$ Global distribution of surgeons, anaesthesiologists, and obstetricians.

http://www.thelancet.com/journals/langlo/article/PIIS2214-109X\%2814\%2970349-3/abstract

15 Increasing access to surgical services in sub-saharan Africa: priorities for national and international agencies recommended by the Bellagio Essential Surgery Group. Luboga S, Macfarlane SB, von Schreeb J, Kruk ME, Cherian MN, Bergstrom S et al. PLoS.Med. 2009 December;6(12):e1000200.

${ }^{16}$ Influenza preparedness in low-resource settings: a look at oxygen delivery in 12 African countries.

Belle J, Cohen H, Shindo N, Lim M, Velazquez-Berumen A, Ndihokubwayo JB, Cherian M. J Infect Dev Ctries. 2010 August 4;4(7):419-24

${ }^{17}$ Equipment Lists and Anesthetic Infrastructure;

http://www.who.int/surgery/publications/immesc_equipt_needsmaneg/en/.

${ }^{18}$ Daniel Vo, Cherian MN, Bianchi S, Noël L, Lundeg G, et al. (2012) Anesthesia Capacity in 22 Low and Middle Income Countries. J Anesth Clin Res 3:207. doi:10.4172/2155-6148.1000207.

${ }^{19}$ Bickler S., Spiegel D. (2010) "Improving Surgical Care in Low- and Middle-Income Countries: A pivotal Role for the World Health Organization.” World Journal of Surgery 34:386-390;

http://www.ncbi.nlm.nih.gov/pmc/articles/PMC2816819/pdf/268_2009_Article_273.pdf.

${ }^{20}$ Pearson L, Shoo R (2005) Availability and use of emergency obstetric services: Kenya, Rwanda, Sudan, and Uganda. Int J Gynaecol Obstet 88:208-215.

${ }^{20}$ Assessment of caesarean delivery availability in 26 low- and middle-income countries: a cross-sectional study. 
providing surgical and anesthetic care services reflect the general shortcomings of districtlevel care, including poor basic infrastructure, lack of essential equipment, lack of communication with and accepting referral facilities, and weak management.

Inadequate information and evidence on surgical and anaesthetic services:In many countries the acute burden of surgically treatable conditions is not well known. In addition, data assessing the number and types of surgical workforce and procedures available at the district-level facilities are not yet systematically part of the national health information system. Although the WHO Situational Analysis Tool to assess surgical (general, emergency, trauma, obstetrics, and anaesthesia) services was utilized in selected African countries, ${ }^{21}$ challenges remain as there is insufficient evidence to answer basic questions about the prevalence and incidence of surgical conditions and the provision of surgical interventions in the African region. Consequently the contribution of surgically treatable conditions to the regional burden of disease and the potential impact of low access to basic surgical services at the first referral level health facility is widely under-appreciated. This lack of information about surgical and anaesthetic services in AFRO hinders evidence-based decision making which would allow for system strengthening.

\section{Challenges}

Inadequate consideration for surgical services in national health plans: The lack of a fully embedded comprehensive surgical care plan within the national health plan has greatly hampered prioritization, innovation and investment in surgical services. For example, provision of surgical services is yet to benefit from the extensive use of telemedicine and ehealth. Furthermore, although surgical services are recognized as a component of comprehensive PHC, their integration in these services is yet to be fully realized. Indeed, existing data show that in many countries, there is no integration of surgical and anaesthetic services in the general health care package.

Inadequate funding for surgical services: The inadequate investment in health services as a whole significantly impacts investment in surgical services. In a majority of countries, investment in health is below US $\$ 44$ per capita, which is the recommended minimum to provide a basic package of services. ${ }^{22}$ Private expenditure on health is both necessary and significant, the bulk of which is from out-of-pocket spending within households that places further limits on access to essential surgical and anaesthetic services. The substantial use of the private sector, partly due to gaps in service delivery in the public facilities, is most often significantly more expensive than the public sector.

\footnotetext{
Ologunde R, Vogel JP, Cherian MN, et al. Assessment of cesarean delivery availability in 26 low- and middle-income countries: a cross-sectional study. Am J Obstet Gynecol 2014;211:x.ex-X.ex.

${ }^{21}$ Deficiencies in the Availability of Essential Musculoskeletal Surgical Services at 883 Health Facilities in 24 Low- and Lower-Middle-Income Countries. Spiegel DA, Nduaguba A, Cherian MN, Monono M, Kelley ET. 2015. World J Surg. 2015 Jun;39(6):1421-32. doi: 10.1007/s00268-015-2971-2.

${ }^{21}$ WHO Situational Analysis Tool Country Assessments http://www.who.int/surgery/publications/topic publications/en/index3.html

${ }^{22} \mathrm{http} / / / \mathrm{dcp}-3$. org/disease-control-priorities-third-edition
} 


\section{Weak referral systems}

In many African countries, patients fail to seek care at health facilities because of economic constraints, inadequate transportation, and fear of or lack of confidence in the quality of care provided. These patients frequently bypass the first level facilities to go directly to the third level. As a consequence, tertiary level hospitals are generally overloaded and do not have enough time to focus on the most complicated cases as they are forced to triage such a large number of less critical patients. This situation results in a disorganized and inefficient referral system in these countries.

\section{Actions Proposed}

The following actions are proposed to address the issues and challenges related to strengthening surgical and anaesthetic services at the district referral level.

Improved advocacy: Collection of evidence on the acute burden of surgically treatable disease and the documented gaps in the provision of existing surgical care in AFRO countries is required to drive advocacy efforts. National governments need to commission evidencebased country assessments to determine their need to strengthen surgical and anaesthetic services at the district referral level. Engaging in further research is critical in order to monitor the effects of appropriate surgical services, and to determine its implications on health systems and public health. In addition, multi-disciplinary stakeholders, including surgical specialists, policy makers, health economists, epidemiologists and social scientists, should collaborate to determine priorities for research and training. Policy makers should encourage funders to support surgical capacity building including system integration, data collection, availability of essential medicines, and adequate workforce development, all aimed towards the delivery of high quality, safe and timely surgical services.

Inclusion of surgical services in the national health plan: Surgery must be seen as part of a basic package of health services and not merely a technical profession, and thus, be fully incorporated in national health polices and strategic plans (NHPSP) ${ }^{23}$.A key component of this will be data collection to allow evidence to drive health policy. Equally important is the focus on implementation of the NHPSP which has been a major challenge in several countries. The required capacity needs to be built and investments made to ensure implementation. Systemic approaches to surgery through people-centred and integrated health services can raise the overall quality and capacity of health care and create an invaluable "ripple effect" of encouraging patients to seek attention for non-surgical conditions. Education targeting the primary level of the health system to allow early recognition, resuscitation and transfer for surgical conditions will be key to effective utilisation of district-level surgical services. Similarly, first-line surgical health services (preventive, diagnostic and curative) should be improved so that common surgical conditions can be diagnosed quickly and appropriate referrals activated. Access to districtlevel hospitals should be increased and referral patterns fortified while tertiary hospitals serve in a strong supportive function. The incorporation of surgical services in the NHPSPcan be promoted by ensuring that a person or unit within the Ministry of Health $(\mathrm{MOH})$ with the

\footnotetext{
${ }^{23} \mathrm{http}: / / \mathrm{www}$. lancetglobalsurgery.org/
} 


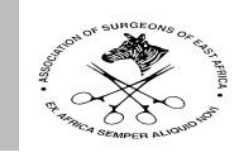

appropriate background is adequately empowered to promote surgical and anaesthetic health care improvements.

Improved access to surgical services: Recent evidence points to a severe surgical workforce deficit in much of AFRO. ${ }^{24}$ Although some surgical procedures require highly skilled staff, a specialist surgeon is not required to perform many of the procedures. ${ }^{2526}$ Some data show that in several countries in AFRO many essential surgeries are performed by nonspecialists. ${ }^{27}$ Strengthening local surgical capacity and task-shifting is an approach that would both provide a high degree of financial protection to populations and increase access to surgical and anaesthetic services in a cost-effective manner. ${ }^{28}$ It is essential, of course, that non-specialist health workers are properly supervised and that their training programs are carefully designed and adequate on-going evaluation. Relatedly, referral mechanisms need to be improved by ensuring adequate capacity to provide surgical services in line with the technical plateau of a given referral level. In addition, ambulance services need to be provided where referral to a higher specialisation level is warranted.

Improved investment by countries and partners: The profound shortage of essential equipment and supplies can only be remedied through appropriate budgetary allocations and ensuring regular deliveries of these supplies to prevent shortages ${ }^{29}$ (refer WHO EEE). Examples include the availability of oxygen and essential medicines for anaesthesia at peripheral health care facilities. There is a need for surgeons and anaesthesiologists to effectively challenge the status quo and advocate for a broader role for surgical services as part of the basic package and its contribution to Universal Health Coverage (UHC). The establishment of a responsible person or unit within the $\mathrm{MOH}$ with the appropriate background would empower them to promote surgical and anaesthetic services and could be held accountable for the established system.

Improved integration for efficiency: Strengthening the delivery of emergency and essential surgical, anaesthetic and obstetric services at the primary care level should be a priority to reduce death and disability. This was highlighted previously in attempts towards achieving the Millennium Development Goals 4, 5 and 6, now replaced by the Sustainable

\footnotetext{
${ }^{24}$ Holmer H, Lantz A, Kunjumen T, Finlayson S, Hoyler M, Siyam A, Montenegro H, Kelley ET, Campbell J, Cherian MN, Hagander L. Global distribution of surgeons, anaesthesiologists, and obstetricians. Lancet Glob Health. 2015 Apr 27;3 Suppl 2:S9-S11. doi: 10.1016/S2214-109X(14)70349-3.

${ }^{25}$ McIntyre T, Zenilman M. “Globalization of Surgery: Let’s get serious.” Arch Surg. 2010; 145(8):715-716; http://archsurg.jamanetwork.com/article.aspx?articleid=406139.

${ }^{26}$ Hodges SC, Mijumbi C, Ok e 1 lo M, McCormick BM, Walker IA, et al. (2007).: Anesthesia services in developing countries: Defining the problems. Anesthesia 62: 4-11.REF: Ouro-Bang'na Maman A, Tomta K, Ahouangbevi S, Chobli M (2005) Deaths associated with anaesthesia in Togo, West Africa.Trop Doct 35: 220222.

${ }^{27}$ Ozgediz D, Galukande M, Mabweijano J,Kijjambu S, Mijumbi C, et al. (2008) The neglect of the global surgical workforce: Experience and evidence from Uganda. World J Surg 32:1208-1215.

${ }^{28}$ Debas, H.T. et al. "Surgery." Jamison, D.T. et al.(2006) Disease Control Priorities in Developing

Countries.2nd. New York, NY: Oxford University Press; 12451260.

${ }^{29}$ REFER WHO EEEE
}

COSECSA/ASEA Publication -East \& Central African Journal of Surgery 2017; Vol. 22 (1) 
Development Goals, particularly Goal $3 .{ }^{30},{ }^{29 B 31}$ Investment in surgical services in an integrated manner with other health care services and between various-level health facilities will strengthen not only hospital services but the health system itself. Such work may be complemented and enhanced by ensuring that the surgical services provided are comprehensive enough to serve the population's basic acute and chronic surgical care needs. Investments in workforce skills and infrastructure must be built to meet the surgical, anaesthesia and obstetric service needs of district hospitals and should be addressed in the comprehensive district health care package. ${ }^{32}$ The presence of a functioning surgical unit at a local district hospital would help to ensure a functioning blood bank, a clinical laboratory, and the emergency transport and communication systems of a hospital, to improve its overall effectiveness. ${ }^{25}$

Monitoring and evaluation: Routine Monitoring and Evaluation systems need to incorporate monitoring of the provision of surgical services. Likewise, health sector joint reviews should also assess progress and achievements made as well as challenges encountered in the provision of surgical services. This will provide a basis for policy dialogue and investment decisions.

Disclaimer: The authors include WHO staff. The views expressed in this publication reflect their views and not necessarily that of WHO.

\footnotetext{
${ }^{30} 17$ Reduce child mortality (4), improve maternal health (5) and combat HIV/AIDS, Malaria and other diseases (6); http://www.un.org/millenniumgoals/.

31 \#29- https://sustainabledevelopment.un.org/sdgs

32 Pereira C, Cumbi A, Malalane R, Vaz F, McCord C, et al. (2007) Meeting the need for emergency obstetric care in Mozambique: Work performance and histories of medical doctors and assistant medical officers trained for surgery. BJOG doi:10.1111/j.1471-0528.2007.01489.x.24.
} 